\title{
Prolonged survival of allogeneic corneal grafts in rabbits treated with topically applied cyclosporin A: systemic absorption and local immunosuppressive effect
}

\author{
B FOETS,' L MISSOTTEN,' P VANDERVEEREN,' ANd W GOOSSENS
}

From the Department of 'Ophthalmology and 'Haematology, Catholic University of Leuven, Belgium

SUMMARY The modes of action of topical cyclosporin A were studied in rabbits. Immunorejection of corneal allografts was provoked by placing the grafts eccentrically, in contact with the limbus. Topical application of cyclosporin A five times daily for 28 days prevented the rejection of corneal allografts. All grafts were rejected in the control animals. The seven rabbits of the cyclosporin A group were subsequently treated for six months with a lower dosage of cyclosporin A $1 \%$. In six rabbits the graft remained clear. One rabbit treated with two drops a day showed an allograft reaction that could be suppressed by increasing the dosage. After six months, discontinuation of the therapy resulted in rejection of all grafts within four weeks. Cyclosporin A could be detected in the plasma and aqueous humour of both eyes at the end of the treatment, raising the question whether the immunosuppressive effect of topically applied cyclosporin A was due to local or systemic action. Cyclosporin A $1 \%$ was therefore applied to the fellow eye five times daily following transplantation, and this treatment, producing similar plasma levels of cyclosporin $\mathrm{A}$, failed to delay the rejection of eccentric corneal allografts. Consequently the suppression of the allograft rejection by topical cyclosporin $A$ is primarily a local immunosuppressive effect, though systemic influence is not ruled out.

Since its introduction by Borel et al.' in 1976 cyclosporin $\mathrm{A}$ has proved to be a powerful non-myelotoxic immunosuppressive agent and has given encouraging results in organ transplantation. Immunological rejection is the main cause of failure of corneal grafts. Administered parenterally it prolongs the survival of corneal allografts in rabbits. ${ }^{2-4}$ However, systemic treatment with immunosuppressive agents may produce severe side effects, which are not acceptable in clinical corneal transplantation. Further improvement of the results of keratoplasties will depend on the development of immunosuppressive agents that can be applied topically to reduce the risk of systemic toxicity.

Hunter and coworkers' first reported the favourable effect of cyclosporin A $1 \%$ eye drops on the survival of corneal allografts in rabbits. They developed a new experimental model in which rejecCorrespondence to B Focts, MD, AZ St Rafaël, Department of Ophthalmology, Kapucijnenvoer 7, B 3000 Leuven, Belgium. tion of corneal allografts is initiated solely by the transplanted corneal antigens. By placing the allografts eccentrically in contact with the limbus, rejection is accomplished in almost $100 \%$ of the cases without additional sensitisation by a second set skin graft. This experimental model closely resembles the situation of corneal grafting in man.

Prolonged survival of corneal allografts in rabbits could be obtained by continuing topical therapy with cyclosporin A $1 \%$ eye drops for 13 weeks ${ }^{6} ; 44 \%$ of the corneal grafts remained clear even for longer than three months on cessation of the treatment. This observation corresponds to results achieved in other experimental organ transplants, where it is sometimes possible to achieve prolonged survival of the allograft following short-term treatment with cyclosporin A. ${ }^{78}$ This paper reports experiments in which we further explore the methods of treatment with topical cyclosporin A $1 \%$ after corneal transplants in rabbits. We used the rabbit model cited above. ${ }^{56}$ 
MATERIALS AND METHODS

Outbred New Zealand albino rabbits were used in this study.

\section{EXPERIMENT 1}

Corneal allografts taken from Dutch rabbits were implanted in the right eye of 15 albino rabbits. The recipient hole, $7 \mathrm{~mm}$ in diameter, was trephined eccentrically in contact with the limbus in the upper temporal quadrant. The donor button, $7.5 \mathrm{~mm}$ in diameter, was fixed with a running nylon 10-0 suture. Surgery was carried out under general anaesthesia (fluanisone $1 \%$ and fentanyl citrate $0.02 \%, 0.5 \mathrm{ml} / \mathrm{kg}$ intramuscularly). In addition a retrobulbar injection of $1 \mathrm{ml}$ lidocaine $2 \%$ was given, and 5000 IU heparin was administered intravenously. All the keratoplasties were performed under an operating microscope by the same surgeon. At the end of surgery a single injection of $40 \mathrm{mg}$ gentamicin was given subconjunctivally. The grafted eyes were divided at random into two treatment groups. Seven eyes were treated with cyclosporin A $1 \%$ in olive oil eye drops and eight eyes with sterile olive oil only. The eye drops were administered five times daily for four weeks after the operation. The evaluation was double blind.

The eyes were checked twice a week for rejection symptoms by slit lamp examination. Criteria for rejection were the occurrence of an inflammatory reaction in the anterior chamber, an endothelial or epithelial rejection line, or oedema of the graft with or without associated superficial or deep vascular penetration in a previously uninflamed eye with a clear corneal graft.

After the fourth week the code was opened and the results analysed. The seven rabbits of the cyclosporin A group were subsequently treated with a lower dose of cyclosporin A $1 \%$ drops. Four rabbits were given one drop four times a day, three rabbits were given one drop of cyclosporin A $1 \%$ twice daily. Weekly slit lamp examinations were done. After six months of topical treatment blood samples were taken from an ear vein to determine cyclosporin A plasma concentrations. Cyclosporin A levels were also determined in the aqueous humour of both eyes. The anterior chambers were punctured under general anaesthesia with a 26 gauge disposable needle through the limbus, and 0.1 to $0.2 \mathrm{ml}$ of the aqueous was aspirated.

Cyclosporin concentrations in blood plasma and aqueous humour were determined by radioimmunoassay ${ }^{9}$ with a kit manufactured by Sandoz Ltd.

Blood samples drawn on heparin were kept at room temperature for two hours prior to separation of blood cells from plasma and subsequent freezing of the latter until the day of analysis. All samples were run in duplicate.

Assay precision tests yielded in our hands intraassay coefficients of variation of $4 \cdot 3 \% \quad(n=20, \bar{x}=$ $110 \mu \mathrm{g} / \mathrm{l})$ and $3 \cdot 8 \% \quad(\mathrm{n}=20, \bar{x}=243 \cdot 7 \mu \mathrm{g} / \mathrm{l})$, and interassay coefficients of variation of $5 \cdot 1 \%(n=10, \bar{x}$ $=87.3 \mu \mathrm{g} / \mathrm{l})$ and $5 \cdot 4 \%(\mathrm{n}=10, \bar{x}=202 \cdot 6 \mu \mathrm{g} / \mathrm{l})$. No modification of the plasma assay system was required for assessing the cyclosporin concentrations in aqueous humour samples.

Six months postoperatively the cyclosporin A $1 \%$ treatment was stopped, but the weekly examinations with the slit lamp were continued. When a rejection became clinically evident, the application of cyclosporin A $1 \%$ eye drops four times daily was resumed.

\section{EXPERIMENT 2}

Fourteen rabbits underwent a penetrating keratoplasty in the right eye in the same way as in the first experiment. At the same surgical session a comparable wound was made in the left eye-a perforating linear incision extending from limbus to limbus in the upper temporal quadrant; this was sutured with a running nylon 10-0 suture. The right eyes with the allografts were treated topically with drops of olive oil.

Cyclosporin A $1 \%$ in olive oil drops was instilled into the left eyes of seven randomly chosen rabbits. The remaining six rabbits received only olive oil drops in their left eye. All eye drops were applied five times daily. Slit lamp examination was carried out twice a week. Weekly blood samples were taken from an ear vein of five rabbits to determine the levels of cyclosporin A."

\section{Results}

\section{EXPERIMENT 1}

Four weeks after keratoplasty the corneal allografts were still clear in all seven rabbits treated with cyclosporin A $1 \%$. At that time, seven out of the eight control rabbits, had already rejected their graft; the last placebo graft was rejected on the 46th day, the median rejection time being 21.5 days. This justifies the conclusion that eye drops containing cyclosporin $\mathrm{A} 1 \%$ applied to the recipient eye five times daily for four weeks delays the rejection of corneal allografts in rabbits (Fisher's exact test, 0.001 $<\mathrm{p}<0 \cdot 01)$.

Prolonged treatment was instituted in the seven rabbits whose eyes had received cyclosporin $\mathrm{A} 1 \%$ eye drops. Four rabbits were given four drops a day, and three rabbits were given two drops a day. Six rabbits retained a clear graft. One rabbit on a maintenance treatment of one drop twice daily rejected its graft on the 63rd day of the therapy. 
Table 1 Concentrations of cyclosporin A $(\mu \mathrm{g} / \mathrm{l})$ in plasma and aqueous humour of both eyes after a six-month topical therapy with cyclosporin A $1 \%$ eye drops in the right grafted eye

\begin{tabular}{lllcc}
\hline Rabbit & $\begin{array}{l}\text { Treatment } \\
\text { frequency } \\
\text { (dropsaday) }\end{array}$ & Plasma & $\begin{array}{l}\text { Right } \\
\text { eye }\end{array}$ & $\begin{array}{l}\text { Left } \\
\text { eye }\end{array}$ \\
\hline 2 & 4 & 136 & 95 & 166 \\
5 & 4 & 233 & 121 & 144 \\
7 & 4 & 60 & 91 & 93 \\
10 & 4 & 151 & 168 & 182 \\
18 & 4 & 187 & 254 & 172 \\
8 & 2 & 119 & 162 & 105 \\
16 & 2 & 113 & 118 & 54 \\
Mean & & $141 \cdot 286$ & $144 \cdot 143$ & $130 \cdot 857$ \\
\hline
\end{tabular}

Progressively increasing penetration of blood vessels arising from the limbus developed, associated with oedema of the graft. Once this graft was entirely cloudy and vascularised, the treatment was increased to one drop of cyclosporin A four times daily, which dose was maintained throughout the rest of the experiment. In a period of two months the vessels regressed and the oedema decreased, resulting in a clear graft with only barely visible ghost vessels. No other medication was used.

The concentrations of cyclosporin A in the plasma and the aqueous humour of both eyes are listed in Table 1. The samples of blood and aqueous humour were taken at the end of the six months of treatment with cyclosporin A $1 \%$ drops into the right, grafted eye. The cyclosporin $A$ levels in the plasma and in the aqueous humour of the right and left eyes were similar, the difference not being significant $(p>0.45$ by the $\mathrm{F}$ test).

One rabbit (no. 2) died as a result of the general anaesthesia required to perform the paracentesis. In the remaining six rabbits, after discontinuation of the treatment, all grafts were rejected with a mean rejection time of 17 days. In one rabbit an epithelial rejection line was visible as early as the seventh day

Table 2 Plasmaconcentrations of cyclosporin A ( $\mu g / l)$, during therapy with cyclosporin A $1 \%$ eye drops, five times a day in the left non-grafted eye

\begin{tabular}{lllrr}
\hline Rabbit & \multicolumn{4}{l}{ Postoperative day } \\
\cline { 2 - 5 } & 7 & 10 & 14 & \multicolumn{1}{c}{21} \\
\hline 1 & ND* $^{*}$ & 257 & 123 & 149 \\
2 & ND & 261 & 84 & 51 \\
11 & 138 & 113 & 80 & 128 \\
13 & 159 & 117 & 64 & 90 \\
14 & 139 & 64 & 29 & 71 \\
Mean & $145 \cdot 3$ & $162 \cdot 4$ & 76 & $97 \cdot 8$ \\
\hline
\end{tabular}

${ }^{*} \mathrm{ND}=$ not donc. after cessation of the therapy. The clinical course of the rejection paralleled that of the control rabbits; there was ingrowth of blood vessels arising from the limbus associated with corneal oedema. An epithelial rejection line was frequently seen and often a quiescent anterior chamber with only a few cells.

As soon as the rejection of the grafts was clinically evident, the topical treatment with cyclosporin A 1\% into the recipient eye, one drop four times daily, was resumed. Gradually thereafter the vessels regressed, and the oedema of the graft decreased in a period of two to four weeks. However, no control group was available to determine the effect of the drug in this process.

\section{EXPERIMENT 2}

Cyclosporin A $1 \%$ or placebo eye drops were applied to the fellow eye, five times daily, in 14 grafted rabbits. One rabbit died as a result of the general anaesthesia; the other 13 rabbits all had a clear allograft in the right eye at the end of the first postoperative week. In seven rabbits cyclosporin A $1 \%$ in oil was applied to the left eye, one drop five times daily; all the right-eye allografts were rejected with a mean rejection time of 23.97 days. In the control group with placebo treatment the mean rejection time was 23.83 days. The plasma levels of cyclosporin A measured on different postoperative days are summarised in Table 2.

\section{Discussion}

The results of experiment $1^{11}$ confirm earlier reports ${ }^{56}$ that cyclosporin A $1 \%$ in oil eye drops applied to the recipient eye inhibit the rejection of corneal allografts in rabbits. A single retrobulbar injection of cyclosporin $\mathrm{A}^{11}$ in oil likewise prolongs corneal allograft survival in rabbits. The minimum dosage required for complete immunosuppression appears to be one cyclosporin A $1 \%$ drop four or three times daily. We observed graft rejection in a rabbit on a maintenance therapy of two drops a day, and rejection occurred when the dosage was reduced to one drop daily in an analogous experiment. ${ }^{\circ}$

After discontinuation of the topical therapy all the grafts were rejected within four weeks, even though the animals had been treated for six months. This is contrary to Hunter and colleagues' findings that $44 \%$ of the grafts treated for three months with cyclosporin A $1 \%$ eye drops remained clear after the end of the treatment. ${ }^{6}$ The most likely explanation of this difference is that we placed the allografts more closely to the limbus. In Hunter and colleagues' experiment reactivation of the corneal blood vessels also resulted in typical corneal rejection in spite of the previous treatment with cyclosporin A. Although 
in our experiment no graft tolerance was induced, short term treatment with topical cyclosporin A could still be useful in clinical corneal transplantation. In the early postoperative period, when lymphocytes migrating in the traumatised eye have easy access to the cornea, the allograft might be protected by cyclosporin $\mathrm{A}$. Later on, when the eye has become quiet, the graft might benefit from the relative immunological privilege of the cornea.

In our study, once the allograft rejection was established and the lymphocytes were accordingly sensitised to the foreign corneal tissue, the signs of rejection could again be suppressed by resuming the topical treatment with cyclosporin A $1 \%$ drops. This observation leads us to suggest that topically administered cyclosporin $\mathrm{A}$ exerts at least some influence on the efferent arch of the immunorejection. The respective parts played by the non-antigen-specific lymphotoxicity of cyclosporin $A$ and the inhibition of the antigen-specific sensitisation of the $T$ lymphocytes are still obscure: 112

Considerable systemic absorption of topically administered cyclosporin $\mathrm{A}$ occurs in rabbits. We found plasma levels of cyclosporin A (Tables 1,2) as high as those recommended for maximal graft survival in man. This raised the question whether in this model topically applied cyclosporin A might exert its immunosuppressive action by way of systemic absorption.

However, this was disproved by the second experiment. Cyclosporin A 1\% eye drops applied five times daily to the fellow eye failed to inhibit rejection of the corneal allograft in the right eye. The mean rejection time in the control rabbits and the animals treated with cyclosporin A was the same, though plasma levels similar to those of the first experiment were observed. These elevated plasma concentrations apparently are too low to inhibit rejection of limbus - touching corneal allografts in rabbits.

Accordingly, the inhibition of the rejection of a corneal allograft by topically applied cyclosporin A $1 \%$ eye drops is due primarily to a local immunosuppressive effect in the cornea, limbus, conjunctiva, and possibly the sclera and regional lymph nodes. A contributory influence of the systemic concentrations (Table 1) is not excluded. The significance of the cyclosporin A levels found in the aqueous (Table 1) needs further study. During paracentesis in rabbits some contamination of the aqueous by plasma is hard to avoid. But even a very short disturbance of the blood-aqueous barrier cannot explain equal distribution of cyclosporin $\mathrm{A}$ in the plasma and the aqueous.

Our test animals did not manifest clinical signs of adverse general effects. In particular, no gastrointestinal toxicity ${ }^{13}$ was observed. Because of the larger human body weight, it is to be expected that the use of cyclosporin A $1 \%$ eye drops in man will result in lower plasma levels, reducing the risk of systemic toxicity. Nevertheless we strongly recommend careful monitoring of cyclosporin A plasma concentrations in patients treated with cyclosporin $\mathrm{A}$ eye drops.

Sandoz Ltd. kindly provided the cyclosporin A and the RIA kit components used in this study.

\section{References}

1 Borel JF, Feurer C, Gubler HU, Stähelin H. Biological effects of cyclosporin A: a new antilymphocytic agent. Agents Actions 1976; 6: 468 .

2 Coster DJ, Sheperd WFI, Chin Fook T, Rice NSC, Jones BR. Prolonged survival of corneal allografts in rabbits treated with cyclosporin A. Lancet 1979; ii: 688-9.

3 Sheperd WFI, Coster DJ, Chin Fook T, Rice NSC, Jones BR. Effect of cyclosporin A on the survival of corneal grafts in rabbits. Br J Ophthalmol 1980; 64: 148-53.

4 Bell TAG, Easty DL, McCullagh KG. A placebo-controlled blind trial of cyclosporin $A$ in prevention of corneal graft rejection in rabbits. BrJ Ophthalmol 1982; 66: 303-8.

5 Hunter PA, Wilhelmus KR, Rice NSC, Jones BR. Cyclosporin A applied topically to the recipient eye inhibits corneal graft rejection. Clin Exp Immunol 1981; 45: 173-7.

6 Hunter PA, Garner A, Wilhelmus KR, Rice NSC, Jones BR Corneal graft rejection: a new rabbit model and cyclosporin $A$ BrJ Ophthalmol 1982; 66: 292-302.

7 Calne RY, Rolles K, White DJG, Smith DP, Herbertson BM Prolonged survival of pig orthotopic heart grafts treated with cyclosporin A. Lancet 1978; i: 1183.

8 Green CJ, Allison AC. Extensive prolongation of rabbit kidney allograft survival after short-term cyclosporin A treatment. Lancet 1978; i: 1182.

9 Donatsch P, Abisch E, Homberger M, Traber R, Trapp M, Voges $R$. A radioimmunoassay to measure cyclosporin $A$ in plasma and serum samples. J Immunoassay 1981; 2: 19-32.

10 Foets B, Vanderveeren P, Missotten L. Inhibition of the allograft reaction in corneal transplantation by cyclosporin $A$ : an experimental study with rabbits. Bull Soc Belge Ophtalmol 1983; 206: 21-6.

11 Salisbury JD, Gebhardt BM. Suppression of corneal allograft rejection by cyclosporin A. Arch Ophthalmol 1981; 99: 1640-2.

12 Kana JS, Hoffmann F, Buchen R, Krolik A, Wiederholt M. Rabbit corneal allograft survival following topical administration of cyclosporin A. Invest Ophthalmol Visual Sci 1982; 22: 686-90.

13 Greatwohl A, Forster I, Speck B. Skin grafts in rabbits with cyclosporin A. Transplantation 1981; 31: 136-8. 